one to the female carrier. The remaining four carriers, so far as is known, have not given rise to any cases.

The paratyphoid. carriers averaged only 26.7 years of age at the time of detection, and the time intervening between infection and identification averaged only three years.

The high percentage of positive Widal reactions in the blood of the carriers here reported is notable. In the carriers of $B$. typhosus, all but two gave either a complete or a partial reaction (twenty-six complete, four atypical). In Cases 23 and 30 , in which the Widal reaction was absent, the possibility of contaminated specimens having been sent for examination must be considered. It might be held that if in the suspected groups the discharges from a greater number of persons in whom the Widal reaction was absent had been examined, more carriers would have been found. In response to such a suggestion, it can be said that in some of the suspected groups the discharges were examined with negative results in from three to twenty-nine persons in whom the Widal reaction was absent, and further, that no later cases occurred in the various communities after these carriers were detected and placed under proper supervision. It is true that in each of three commimities one case of typhoid fever occurred following the detection of their respective carriers, but on investigation the infection was traceable in each instance to the negligence of the already identified carricr (Cases 5, 7 and 34).

Certain factors which tend to stasis in the gallbladder are thought to have their influence on the development of cholecystitis and cholelithiasis. These factors, many of which are present in those advanced in years, or in women, have often been enumerated in explanation of the fact that gallbladder troubles are more prevalent after middle life than before, and in women than in men. If this explanation of the age and sex incidence of gallbladder infections is correct. then we should expect to find a higher proportion of carriers in those who undergo a siege of typhoid fever late in life and in women rather than in the young and in men.

In our routine series, the average age at time of infection, over 40 years, appears strikingly suggestive when it is remenbered that typhoid fever is most prevalent among the young. The proportion of female to male carriers in this series, $5: 1$, appears to tally fairly closely with the sex incidence of cholecystitis and cholelithiasis in general.

It is regretted that a more complete study of the cases in the institutional series could not have been made. Possibly a knowledge of the age incidence of the infection of the identified carriers in this series would explain the lesser proportion of female to male carriers.

The Profession in the Netherlands.-Some recently pul)lished statistics show that there are 3,167 physicians in the Netherlands (population over 6 millions). The number of those who obtained elsewhere their license to practice is 2,497 . There are 1,695 medical students in the various universities, including 224 women. This is an increase over a year ago when the figures were respectively 1,521 and 175 . In 1915 there were 1,565 and in 1914, 1,790. The mobilization of the troops explains the drop since. There are thirty-three asylums for the insane, and they are caring for 7,549 men and 7.464 women, a total of 15,013 , an increase of 500 over last ycar.

\section{RAPID REDUCTION OF INTRA-OCULAR TENSION IN GLAUCOMA}

BY TIMED INTRAVENOUS GLUCOSE INJECTIONS *

\section{W. D. SANSUM, M.D. \\ CHXCAGO}

In the course of studies with timed intravenous injections of sugars, salts, etc., several phases of which have been previously reported by Woodyatt, Sansum and Wilder, ${ }^{1}$ observations have been made on possible clinical uses of the rapid dehydration of the organism which may be produced when sugar or salts are injected uniformly into the vein at rates which lead to the excretion of water through the lichneys faster than water is administered with the sugar or salt.

When glucose is injected by vein uniformly at or below the tolerance limit which, in normal resting individuals, lies as a rule between 0.8 and $0.9 \mathrm{gm}$. per kilogram of body weight per hour, there is no increase in the rate of diuresis greater than can be accounted for by the extra water given." In fact, a clefinite antidiuretic tendency manifests itself. But when glucose is injected so fast as to produce a sufficiently rapid excretion of glucose, increased diuresis results; and then if the water injected with the glucose is less than that excreted in the urine, the tendency is toward dehydration. By employing 36 to 54 per cent. glucose solutions and injecting them at rates corresponding to from 3.6 to $5.4 \mathrm{gm}$. of glucose per kilogram per hour, heavy glycosuria and rapid dehydration occur.

The question arises as to whether or not and to what degree fluid can be drawn to advantage from a localized area such, for example, as a blister, an effusion in a serous cavity, a glaucomatous eye, or the like. An opportunity for experimental study presented itself when Dr. E. V. L. Brown asked that we attempt to lower the intra-ocular tension in a certain case of glaucoma then under his observation. Three successful attempts with this case led to the application of the same principle in a second case on the service of Dr. William H. Wilder. 'The results obtained are reported in the belief that the principles and methods employed will be found of clinical interest. It is not improbable, however, that the details of the operation as here described might to advantage be modified, since it would appear that the dehydration was unnecessarily rapid and that equivalent beneficial results might be attained with less risk of harm by a more gradual procedure.

REVIEW OF TIF, LITERATURE

The abstraction of fluid from the body as a whole, including the eye, is by no means a new idea in the mamagement of glaticoma, for among the accepted treatments are frec elimination by sweating, diuresis and catharsis. Local abstractions of fluid by the application of lecches or the subconjunctival injection of salts are also well known proceclures. According to Fischer's theory of glaucoma, the condition constitutes essentially a local edema, a swelling of the ocular colloids, especially of the vitreous, due to an increased

* From the Otho S. A. Sprague Memorial Institute for Infectious Discases, Rush Medical College

1. Woodyatt, R. T., Sansum, W. D., and Wilder, R. M.: Prolonged and Accurately Timed Intravenous Injections of Sugar, TuE Jouks A. M, A., Dec. 11,1915 , p. 2067 . Woodyatt, R. T.: Siudies in Inter mediate Carbolydrate Metabolism, Ilarvey Society Lecture, in linter-

2. Wilker, R. M., and Sansum, W. D.: d. Glucose Tolerance in Health 2. Wilcer, R. M., and Sansum, W. D.: d Cilucose Tole

3. Wootyatt, R. T., and Sansum, W. D.: Jour. Biol. Chem., 1917, 30, 155 .

4. Fischer, M. H.: Arch. f. d. ges. Physiol. (Pflïger's), 1908, 125, 396; 1909, 127, 1 . 
affinity of the colloids for water. $\Lambda$ s salts in suitalle concentrations may cause the separation of water from swollen protein gels, so in an analogous manner they may lower the tension of an eye. On the basis of experiments showing the parallel effects of salts on enucleated eyes and on protein gels, Hayward and Fischer" suggested both local and general treatments, the former consisting in subconjunctival injections of from eighth molecular to sixth molecular (from 4.05 to 5.41 per cent.) sodium acctate solutions, the latter in rectal administration of from 1,000 to 1,500 c.c. of Fischer's hypertonic salt solution. Both in their hands gave beneficial results. Hertel ${ }^{6}$ used hypertonic salt solutions to lower intra-ocular tension as a preliminary step to iridectomy. He reports one case in which, following the intravenous injection of 120 c.c. of a 10 per cent. solution, the intra-ocular tension fell from 72 to $30 \mathrm{~mm}$. of mercury. The time or rate of injection was not stated. In another case following the oral administration of 200 c.c. of the same solution, the tension was lowered from 80 to $22 \mathrm{~mm}$. of mercury. He also used hypotonic solutions to restore ocular tension in the hypotonia found in such conditions as diabetic coma. In this connection it is interesting to note in anticipation of what follows that the "soft eyeball" which may be encountered in diabetes would appear to be merely a part of that general dehydration of the body which goes hand in hand with sugar diuresis and other manifestations of the effects of excessive quantities of free glucose in the body.

\section{TECHNIC}

The glucose employed was a chemically pure product prepared in this laboratory. The details of its preparation are described clsewhere. ${ }^{3}$ The water was freshly distilled with the same precautions as are observed in its preparation for salvarsan administrations. Approximately 2 to 3 molecular (36 to 54 per cent.) glucose solutions were made up by weight, carefully filtered and sterilized in the autoclave. The exact titer was then determined in each case by the polariscope. The volumetric pump has been described in detail in a recent communication.? The details of operation, with the arrangement of the apparatus, also have been described elsewhere. ${ }^{2}$ The rate of injection will depend on the titer of the solution used, the nature of the case, and the quantity of water it is desired to abstract from the body in a specified time. The slower rates of injection extending over two hours or more tend to eliminate the chill and lessen the dangers attendant on the too rapid increase of intravascular pressure and clecrease of intra-ocular tension. Other things being equal, the higher the rate of glucose injection and the less the water given with the glucose, the greater the dehydrating power. A 54 per cent. solution given at a rate corresponding to 3.6 $\mathrm{gm}$. of glucose per kilogram per hour (that is, 6.66 c.c. of a 54 per cent. solution per kilogram per hour) has greater dehydrating power than the same quantity of glucose given in the same time in the form of a 36 per cent. solution (that is, 10 c.c. of a 36 per cent. solution per kilogram per hour). With a solution of fixed concentration (as 54 per cent.), the degree of dehydration will be proportional to the quantity given in a specified time. The intra-octular tension was taken with a Gradle-Schiötz tonometer by the ophthalmologists in charge of the case.

5. Hayward, G. T., and Fischer, M. H.: Ann. Ophth., 1910, 19, 40 6. Wertel: Arch. f. Ophth. (Sattler), 1915, 90, 309.
CASE JUISTORIES AND EXPERIMENTS

CAse 1.-This was one of syphilitic iritis plastica with secondary glaucoma on the service of Dr. E. V. L. Brown, who provided the following history:

Iistory.-Mrs. S., colored, widow, aged 52, was admitted to the Cook County Hospital, Dec. 1, 1915, complaining of pain and swelling in the left eye, photophobia, headaches, joint pains and a fading maculopapular eruption on the body. The eye troulsle had begun about two weeks before admission with redness and photophobia in the left eyc followed by failing vision and joint pains which grew progressively worse. The rash, accompanied by sores in the mouth and headaches, had appeared aloout six weeks prior to admission. The past listory was negative.

Physical Examinalion.-The patient is a fairly well developed but poorly nourished negress. She appears ill and as if she had recently lost in weight and strength.

Eyes: There is slight edema of the conjunctiva of the right eye. The left eyc is nearly closed, owing to edema of the lids. There is profuse lacrimation and chemosis of the bulbar conjunctiva. The cornea is dulled and everywhere overstrewn with epithelial pits. The stroma is clear. There is no gross keratitis punctata. There is marked ciliary and conjunctival injection Two thirds of the anterior chamler is obliterated totally in the sector corresponding to that between $I$ and VII of the clock dial, and half obliterated in the sector between VII and I by the anteriorly displaced iris. The central one fourth of the chamber is normal in depth. The very irregular, $2 \mathrm{~mm}$. pupil is completely encircled by postcrior synechias, and is blocked by a greenish white, nonvascular exudate. There is a sail-like forward bulging of the body of the iris (iris bombr). There are no condylomas or tulerculous nodes, although the iris is furrowed radially from the pupillary border one-half way to II of the clock dial and less deeply to XI. The iris markings are blurred, but otherwise the tissue is not much changed. The crystalline lens and entire back of the cornea are covered by very fine discrete gray flecks of exudate. R. V., $3 / 10 ; L$. V., shadows. Tension, right, $18 \% / 4$; left, $54 \mathrm{~mm}$. of mercury. The synechiae are uninfluenced by the usc of atropin.

Mouth: One small area suggests a mucous patch. Neck: There is cervical and submaxillary adenopathy. Chest: Negative. The heart tones and borders are normal. Blood pressure, 135 systolic and 80 diastolic. Genitalia: There is inguinal and femoral adenopathy. Extremities: There is marked epitrochlear adenopathy. Skin: Across the forehead, about the eyes, and on the upper forearms are numerous split-pea sized, flat, slightly elevated papules which appear a little darker than the normal skin. Laboratory: Urine, normal. Wassermann reaction in the blood plasma $++t$ Complement fixation test for gonorrheal infection in the blood plasma + .

Therapcutic Dehydration.-An iridectomy for the immediate relief of pressure would have been the procedure of choice; but, owing to the fear of complications, such as prolapse of the iris and intra-ocular hemorrhage from the too sudden lowering of tension, the surgeon preferred, if possible, to operate under more favorable conditions. The proposal was therefore made to attempt the reduction of intra-ocular tension by general means. December 6 , after a careful pliysical examination had clemonstrated a sound cardiovaseular-renal system with the blood pressure within normal limits, the patient received 41.2 per cent. glucose solution by vein at the rate of 11.2 c.c. per kilogram per hour for sixty-nine minutes. The $47.5 \mathrm{~kg}$. patient thus received in sixty-nine minutes a total of 612 c.c. of 41.2 per cent. glucose solution containing $252 \mathrm{gm}$. of glucose and approximately 471 c.c. of water. As the restilt of the injection, the patient passed 2,247 c.c. of urine, as against the 471 c.c. of water injected with the glucose, therclsy creating a water deficit in the body of 1,776 c.c., or 37.4 c.c. per kilogram. The blood pressure before the operation was 135 systolic and 80 diastolic. During the injection it rose to $155-100$, and after the injection it fell to $95-65$, systolic and diastolic, respectively. On the following morning at $10: 30$ it had risen to 120 systolic and 90 diastolic. The 
temperature before the injection was $98.4 \mathrm{~F}$. One hour after the injection it was 102 . It then gradually declined to normal in the course of twenty-four hours. Toward the end of the injection for twenty minutes the patient shook as though in a chill, but did not complain of any discomfort. The intra-ocular tension before the injection was $60.5 \mathrm{~mm}$. of mercury and fell to $26 \mathrm{~mm}$. In the right or normal eyc it fell from 15.25 to 12.25. The fall in tension was so striking that the question was raised as to whether if the operation were repeated and followed by a suitable after-treatment the advantage gained might not be maintained for a long enough time to preclude the necessity of operation entirely.

Second Dchydration.-December 14, the treatment was repeated. This time an effort was made to abstract the water more gradually. The patient received a 38.9 per cent. glucose solution by vein at the rate of 8.7 c.c. per kilogram per hour for 108 minutes. The $45 \mathrm{~kg}$. patient thus received in 108 minutes 702 c.c. of 38,9 per cent. solution containing $273 \mathrm{gm}$. of glucose and approximately 548 c.c. of water. $\Lambda$ s a result of the injection the patient passed 2,359 c.c. of urinc while receiving 548 c.c. of water with the glucose, thereby creating a water deficit in the body of 1,811 c.c., or 40 c.c. per kilogram. The tension in the left eye fell from 54 to $18 \mathrm{~mm}$. of mercury. In the right or normal eye it fell from 15.25 to 7.25 . In this instance the blood pressure reached a maximum of $185 \mathrm{~mm}$. There was a "chill" lasting forty minutes. The temperature rose to 102.2. The after-treatment consisted in the limitation of the total water intake to 2,000 c.c. in twenty-four hours, with fifteen doses each consisting of $1 \mathrm{gm}$. of solium bicarbonate and $0.66 \mathrm{gm}$. of sodium acetate with compound jalap powder and magnesium sulphate enougl to produce three or four watery stools daily. The after-treatment failed. The patient complained of thirst, and the intra-ocular tension gradually rose, reaching $44 \mathrm{~mm}$. of mercury by the end of twenty-four hours, when the treatment was stopped because of nausea. After this the tension gradually rose, reaching 47 in three days and 66.75 by the end of a week.

Third Dchydration.-This was performed, December 21, as a preliminary measure to an iriclectomy. The procedure was carried out still more slowly than in the second injection. The patient received 36 per cent. glucose solution at the rate of 7.7 c.c. per kilogram per lour for 115 minutes. Thus the $45 \mathrm{~kg}$. patient was given 662 c.c. of 36 per cent. solution, containing $238 \mathrm{gm}$. of glucose and approximately 530 c.c. of water. The urine totaled 2,275 c.c., while 530 c.c. of water were injected with the glucose. A water deficit of about 1,745 c.c., or 39 c.c. per kilogram, was therefore produced. Although nearly as much water as before was abstracted, the time consumed was longer, and there was in this instance no chill. The temperature rose to 101 . The systolic blood pressure reached 148 and the diastolic $100 \mathrm{~mm}$. of mercury. The intra-ocular tension was reduced from 66.75 to 37.75 . This reading was taken just before the close of the injection; lut at the time of operation, thirty minutes later, it was normal to palpation. Iridectomy was then performed by Dr. Brown. The patient was put on an antisyphilitic management and made an uneventful recovery. The cornea hecame clear. The hyperemia and the anterior synechiac disappeared. The tension remained so low that it was impossible to make satisfactory readings.

The foregoing results were taken to demonstrate the feasibility of lowering intra-ocular tension in a case of the type described; but the question remained as to whether or not parallel results could be obtained in a case of so-called primary glaucoma.

CASE 2.-This was one of very severe acute, primary glaucoma that developed after the patient had heen in the hospital about a month and in spite of careful medicinal and surgical management. The patient was one of Dr. W. $\mathrm{H}$. Wilder, who kindly furnished the history.

History.-Mrs. Janc G., aged 46, with glaucoma, was first examined by me, Jan. 1, 1916. Slie gave a history that one and a half years before the sight of the right eye began to fail, and examination by a specialist revealed that the fields were contracted. Alsout June 1, 1916, she noticed that the central vision of the right eye was much reduced. At times she has had pain in the eyes and has noticed rainbows about a light. Recently the sight of the left eye has been clouded, especially so when she feels nervous.

$$
\text { R. V. with sph. } 6.00 \text {, cyl. } 2.00 \text {, axis } 90^{\circ} \quad 20 / 70
$$

Disks: The right is decply cupped, about $2 \mathrm{~mm}$. In the left there is a deep physiologic cup, but the edges are normal The vessels are somewhat congested. The intra-ocular tension in the right eye is 55 and in the left $25 \mathrm{~mm}$. of mercury. Ficlds: It is impossible to chart the fields of the right eye. In the left eye the white is somewhat contracted above and below. The red reads : above, $18^{\circ}$; below, $18^{\circ}$; nasal, $18^{\circ}$, and temporal, $55^{\circ}$. The green reads: above, $10^{\circ}$; below, $10^{\circ}$ nasal, $12^{\circ}$, and temporal, $40^{\circ}$.

I advised an operation on the right eye and later on the left eye if the tension should become increased. June 26 , 1916, at the Presbyterian Hospital I did an Elliot trephining on the right eye with good results. About two weeks later the tension in the left cyc became high and the patient had an acute attack of glaucoma in this cye. July 14,1 did an iridotasis on the left cye and at the same time an iridectomy on the right eyc, for the tension in that had risen again. The riglit eye quieted down following this iridectomy. The left eye recovered well from the iridotasis and remained low or normal for a few days, when the patient again had an acule attack of glancoma with a tension up to $60 \mathrm{~mm}$. of mercury, shallow anterior chamber, and violent pain requiring narcotics.

Therapoulic Ditydration.-An iridectomy for the immediate relief of pressure would have been the operation of choice; owing, however, to the fear of complications, such as prolapse of the iris and intra-ocular hemorrhage from the too sucklen lowering of tension, the surgeon preferred to work under more favorable conditions. Knowing of the work on the previous case, Dr. Wilder asked that we attempt to lower the tension in this case by the intravenous injection of glucose in preparation for an iridectomy. A careful physical examination showed that the heart, blood vessels and urinary system were in sufficiently gond condition. The systolic blood pressure was 146 and the diastolic $100 \mathrm{~mm}$. of mercury. There was a marked edema of the lids and surrounding tissues. The intra-ocular tension was $60 \mathrm{~mm}$. The anterior chamber was obliterated. July 20 , the pationt received 55.2 per cent. glucose solution hy vein at the uniform rate of 10 c.c. per kilogram ner hour for seventy-six minutes. The $60 \mathrm{~kg}$. patient thus received 691 c.c. of 55.2 per cent. glucose solution containing $380 \mathrm{gm}$. of glucose and approximately 491 c.c. of water. As a result of the injection there was passed 1,250 c.c. of urine as against 491 c.c. of water injected with the glucose, thereloy creating a water deficit in the body of 759 c.c., or 13 c.c. per kilogram. The intra-ocular tension as observed lyy Dr. W. H. Wilder fell from 60 to $20 \mathrm{~mm}$. of mercury. There was no chill. The temperature rose to a maximum of 101. The iridectony was then performed by Dr. Wilker under light ether anesthesia. Before and during the first part of the injection the patient suffered greatly from pain in the eye and was very restless. During the latter part the pain wholly disappeared, and the patient became quiet and went to sleep. The cdcma of the lids and surrounding tissues disappeared cutircly wider the eyes of the observers during the injection. The anterior chamber remained very shallow. The high rate of injection was chosen in this instance because the patient had been taking large doses of morphin which it was feared might retard the liberation of water, although it was not known by experiment that such would be the case. Dr. Wilcler provides the following notes on the subsequent clinical history of the case:

Subseguent History-Before the iridectomy, July 20, 1916, the tension was lowered by the intravenous injection of glucose solution by Dr. Sansum and Dr. R. M. Wilder. This lowered the tension to $20 \mathrm{~mm}$. of mercury, and an iridectomy was satisfactorily done under ether narcosis administered by Dr. Herb. The eye quieted after this operation, and in one week the patient left the hospital. The tension remained 
normal, but the patient continued using 1 per cent. physostigmin (eserin) and 5 per cent. ethylmorphin bydrochlorid (dionin). She was weak for some time, and the elixir of iron, quinin and strychnin was prescribed. The tension seemed increased at times. Feb. 10, 1917, it was $35 \mathrm{~mm}$. Feb. 21, 1917, R. V. 0; L. V. with sph. 200, cyl. 5.50, axis $15^{\circ} 20 \% 0$ These lenses were ordered in tinted glass and the pliysostigmin and ethylmorphin hydrochlorid continued. The right optical disk was deeply cupped and the left slightly cupped.

\section{COMMENT}

The theory of the nature and mechanism of glucose diuresis has been discussed elsewhere and need not be repeated here. The increased temperature observed with each of the injections is a phenomenon which we have encountered in the course of intravenous glucose injections in animals when dehyclration has been pushed beyond a certain degree. The same applies to the chill. A discussion of the theoretical significance of the fever and chill would be irrelevant in this place. The increased blood pressure is associated with the increased blood volume due to the flow of water into the blood owing to the presence in the blood of increased quantities of free glucose. ${ }^{8}$

Attention is directed to the temporary but marked elevation of blood volume and blood pressure during the intravenous injection of glucose because an injudicious application of the principle of intravenous sugar or salt injection to cases in which the cardiovascular system was impaired might lead to deleterious effects. In the cases here reported the treatment was not instituted without a careful preliminary consideration of the heart, vessels and renal function. A powerful procedure such as this, which is capable of radically lowering intra-ocular tension and simultaneously elevating the intravascular tension, should obviously not be undertaken blindly or without due care in cases in which the condition of the vessels, especially those within the eye, would render them liable to rupture by a too rapid change of pressure relations. As stated at the outset, the details of the operation as here described are not presented as necessarily the most appropriate for clinical work generally. They might be modified in other cases and in the light of further experience.

By a suitable selection of the rate of glucose injection and of the quantity of water abstracted in a given time, it should be possible to control to a nicety the rate and degree of ocular pressure reduction to meet the demands of the ophthalmologist. In this connection it may be noted that the possibility of positive control is greater than it is in the ordinary local operative procedures which are in general use by ophthalmologists.

The experiments demonstrate without any question the possibility of quickly lowering intra-ocular tension in the types of glaucoma described and in the normal eye.

It is not the purpose of the present report to decide when a procedure of the kind herein described should have the preference over other lnown resources in ophthalmologic practice. It appears to offer a means of lowering intra-ocular tension to a degree and at a rate chosen by the surgeon either in a normal or a glaucomatous eye. It would appear to be a method particularly sensitive to control and especially fitted to meet the demands for a rapid temporary reduction of intra-ocular tension to prevent the damaging effects of

8. Compare Iusk: Jour. Biol. Chem., 1912, 13, 27. Fisher and Wishart: Ibid., 1912, 13, 49. Woodyatt and Sansum (Irootnote 3) mechanical pressure and to pave the way for a surgical operation which cannot be safely or satisfactorily performed with the existing intra-ocular tension. The advantages or disadvantages of the method as compared with cyclodialysis, sclerotomy, etc., could be stated only after further investigation by specialists.

\section{IIOOKWORM CONTROL IN SOUTII CHINA}

HASED ON A I'RLLIMINARY STUDY OF TIIE INCIDENCE OF IIOOKWORM INFECTION IN IIUNAN IROVINCE, CIIINA

EDWARD H. HUME, M.D.

CHANGSHA, CHINA

The problem of the control of hookworm infection in South China differs in so many essentials from the same problem in America and in other Western countries that its solution will require long planning by specialists and a persistently carricd out program of practical endeavor. In many of the American states, the carelessly built latrine, or its total absence, has made soil pollution frequent. In India, in the rural districts, human excrement is deposited directly on the soil, but without any organized system of using it for fertilizer. In Soutl China, however, it is the custom to collect it in earthen jars and to ladle it out from these into buckets to be hurried out to the ficlds and gardens for fertilizer. Each farmer or gardener has a little cesspool into which the bucket contents are poured for storage. Fertilization is not limited to manuring the ground, but, especially in vegetable gardens, suitable aqueous dilutions of the pool contents are sprinkled over the growing crop at appropriate intervals, the human excrement being literally smeared over the vegetable leaf. Later, when these vegetables reach the kitchen, they frequently receive cooking that falls far short of sterilization. With such methods of enrichment, followed by scant cooling, the wonder is, not that some of the people have intestinal disease and parasitic infection, but that any one escapes. We may thus note at the outset that the study of hookworm in China is complicated by many factors not present in other lands. Some of these are:

1. The aniversal use of human excrement for fertilizer.

2. The consequent and continuous discharge of effluent, containing parasitic ova and larval forms, into streams. contaminating both their waters and the soil of their banks.

3. The presence of disease due to other animal parasites, such as Schistosoma japonica, whose symptomatology resembles, in so many ways, that of hookworm infection.

4. The frequency of concurrent infection with hookworm and malarial or other fevers, rendering it difficuit to gage the exact morbid significance of each.

It is my purpose, in this paper, to present a summary of recent surveys made to determine the extent of hookworm infection in Hunan province, and to discuss, in the light of these surveys, some of the factors bearing on its control in South China.

\section{HISTORICAL DATA}

Jefferys and Maxwell' have pointed out that hookworm is to be found over wide areas of the country,

1. Jefferys, W. H., and Maxwell, J. L.: Discases of China, Including Formosa and Korca, Philadelphia, P. Blakiston's Son \& Co., 1910. 